\title{
USO DE ADITIVOS PROMOTORES DE CRESCIMENTO SOBRE O DESEMPENHO, CARACTERÍSTICAS DE CARCAÇA E BACTÉRIAS TOTAIS DO INTESTINO DE FRANGOS DE CORTE ${ }^{1}$
}

\author{
Use of growth promoters additives on performance, carcass yield and total \\ intestinalbacteria counts in broiler \\ Éder Clementino dos Santos ${ }^{2}$, Antônio Soares Teixeira ${ }^{3}$, Rilke Tadeu Fonseca de Freitas ${ }^{3}$, \\ Paulo Borges Rodrigues ${ }^{3}$, Eustáquio Souza Dias ${ }^{4}$, Luis David Solis Murgas ${ }^{5}$
}

\begin{abstract}
RESUMO
Objetivou-se com este trabalho foi avaliar o efeito de aditivos promotores de crescimento em substituição ao antibiótico sobre o desempenho, características de carcaça (partes e gordura abdominal) e bactérias totais do intestino delgado e cecos de frangos de corte de 1 a 42 dias de idade, criados em cama reutilizada e alimentados com rações à base de milho moído e farelo de soja. O delineamento experimental utilizado foi o inteiramente casualizado, com um arranjo fatorial 7 x 2, correspondendo a 7 fontes de aditivos (antibiótico, basal, mananoligossacarídeo (MOS), frutoligossacarídeo (FOS), ácido fumárico, cogumelo desidratado e probiótico) e dois sexos (macho e fêmea). Foram utilizados um total de 1680 pintos, sexados, da linhagem Hybro, distribuídos em 14 tratamentos com 04 repetições e 30 aves por parcela experimental. Foi observado efeito significativo $(\mathrm{P}<0,05)$ dos aditivos promotores de crescimento sobre a conversão alimentar, eficiência alimentar e fator de produção e verificou-se que o sexo foi influenciado no desempenho de frangos de corte, exceto viabilidade. Os aditivos influenciaram positivamente o rendimento de carcaça, partes e gordura abdominal, sendo que os machos apresentaram melhores resultados de peso ao abate e rendimento de coxa, em relação às fêmeas. Houve efeito somente dos aditivos sobre a contagem total de bactérias do conteúdo intestinal do duodeno e cecos, sem portanto, efeito do sexo sobre estas variáveis. As mudanças ocorridas na microbiota intestinal podem ter contribuído para uma sobrevivência estável de microorganismos no ecossistema intestinal, proporcionando benefícios ao animal hospedeiro. Conclui-se que os aditivos promotores de crescimento podem ser utilizados na alimentação para frangos de corte, em substituição ao antibiótico, sem comprometer o desempenho e características de carcaça, no período de 1 a 42 dias de idade.
\end{abstract}

Termos de indexação: Antibiótico, desempenho, frangos de corte, promotores de crescimento, rendimento carcaça.

\section{ABSTRACT}

The objective of this study was to evaluate the effect of growth promoters additives on performance, carcass yield (parts and abdominal fat), total intestinal bacteria counts in broilers from 1 at 42 days old fed with corn and soybean meal based diets, compared to antibiotics supplementation diets. In this study were urilized a 7 x 2 factorial design, with seven differents additives (antibiotic, basal, MOS, FOS, fumaric acid, mutshroom extract and probiotic) and two sex (males and females). A total of1680 sexed broilers chickens from Hybro line were distributed in 14 treatments, with 4 replicates and 30 chickens per experimental unit. Effects of growth promotant additives on feed intake, feed conversion and production efficiency factor were measured. Male chickens shown better performance results than females in all parameters evaluated, except for viability. Additives shown positive effects on carcars yield, parts yield, and abdominal fat. Male chickens were heavier at slaughter and shown higher leg yields than females. Additives also influenced total bacteria counts in duodenum and caecum altering the microbiota of the intestinal chickens. These changes in intestinal microbiota might have contributed for a higher stability and better survival of good microorganisms in the intestinal ecosystem, resulting in benefits for the host. The results of this study shown that the use the addictive as a growth promoters should be used in the feeding for broilers chickens, in substitution to the antibiotic, without affecting the performance and carcass yield, in the period from 1 to 42 days of age.

Index terms: Antibiotic, broilers chickens, growth promoter, performance, carcass yield.

(Recebido para publicação em 30 de junho de 2003 e aprovado em 20 de setembro de 2004)

\section{INTRODUÇÃO}

A tecnologia empregada no setor avícola tem procurado otimizar a produção, para atingir melhores resultados econômicos e produzir um alimento mais seguro e saudável para o consumidor. Neste sentido, a avicultura tem se desenvolvido extraordinariamente, devido aos avanços em áreas como genética, nutrição, manejo e sanidade. No entanto, é constante a busca por alternativas que aumentem a produtividade animal,

\footnotetext{
1. Parte da tese apresentada à Universidade Federal de Lavras pelo primeiro autor, para obtenção do titulo de Doutor em Zootecnia, na área Nutrição de Monogástricos - Caixa Postal 3037 - 37.200-000 - Lavras, MG.

2. Professor da Escola Agrotécnica Federal de Inconfidentes - Praça Tiradentes - Centro - Inconfidentes, MG - 37.576-000.

3. Professor do Departamento de Zootecnia/UFLA

4. Professor do Departamento de Biologia/UFLA.

5. Professor do Departamento de Medicina Veterinária/UFLA.
} 
melhorem a qualidade dos produtos finais e reduzam os custos de produção, sem prejudicar o desempenho zootécnico (Santos et al. 2002). É comum o uso de antibióticos em dietas de frangos de corte, como promotores de crescimento na forma subterapêutica, tendo mostrado grandes benefícios na produção animal, principalmente por melhorar o ganho de peso e conversão alimentar e reduzir a mortalidade. No entanto, existe uma preocupação crescente de que o uso de doses sub-clínicas de antibióticos na alimentação animal atue como fator de risco à saúde humana, devido a presença de resíduos em produtos animais para o consumo humano, que podem produzir reações alérgicas, toxicidade ou indução de surgimento de resistência bacteriana.

As campanhas de banimento de antimicrobianos na produção de aves e a opinião pública têm prevalecido na restrição dos antimicrobianos na alimentação animal, e diversos aditivos têm sido usados nas rações avícolas como alternativas aos antibióticos, dentre os quais os mananoligossacarídeos, os frutoligossacarídeos, o ácido fumárico, o cogumelo desidratado e os probióticos (SANTOS et al., 2002b). Esses aditivos têm proporcionado condições favoráveis ao desenvolvimento de microrganismos benéficos do trato gastrointestinal, resultando em melhor digestão e absorção de nutrientes, além de melhorar a qualidade dos produtos finais, sem causar riscos ao consumidor (FUINI, 2001; SANTOS et al., 2002b).

Conduziu-se este trabalho com o objetivo verificar os efeitos da utilização de aditivos promotores de crescimento sobre o desempenho, características de carcaça e contagem de bactérias totais do intestino delgado e cecos de frangos de corte no período de 1 a 42 dias de idade.

\section{MATERIAIS E MÉTODOS}

O experimento foi realizado no galpão experimental do Setor de Avicultura da Escola Agrotécnica Federal de Inconfidentes, MG, Brasil (EAFI). Foram utilizados 1680 pintos de corte de um dia, da linhagem Hybro, que foram sexados e pesados antes de serem alojados nas unidades experimentais. Os tratamentos utilizados foram dieta basal (controle - sem aditivos), dieta basal + antibiótico Surmax ${ }^{\circledR}$ (avilamicina - $10 \mathrm{ppm}$ ), dieta basal + mananoligossacarídeo (Bio-Mos Alltech ${ }^{\circledR} 1,0 \mathrm{~kg} / \mathrm{t}$ ), dieta basal + frutoligossacarídeo (FOS-P Power ${ }^{\circledR} 300$ $\mathrm{g} / \mathrm{t}$ ), dieta basal + ácido fumárico Feed Grade PETROM $^{\circledR}(10,0 \mathrm{~kg} / \mathrm{t})$, dieta basal + cogumelo desidratado $(2,7 \mathrm{~kg} / \mathrm{t})$ e dieta basal + probiótico (Viva
Vida Plus Interchange $\left.{ }^{\circledR}-1,0 \mathrm{~kg} / \mathrm{t}\right)$, composto por Lactobacillus acidophillus $\left(5,4 \times 10^{11} \mathrm{UFC} / \mathrm{g}\right)$, L. casei, Streptococcus lacteis $\left(5,4 \times 10^{11} \mathrm{UFC} / \mathrm{g}\right), \mathrm{S}$. Faecium $\left(5,4 \times 10^{11} \mathrm{UFC} / \mathrm{g}\right)$, Bifidobacterium bifidum $\left(5,4 \times 10^{11}\right.$ UFC/g) e Aspergillus oryzae $\left(5,4 \times 10^{11} \mathrm{UFC} / \mathrm{g}\right)$. Os aditivos promotores de crescimento foram adicionados nas dietas segundo as dosagens dos respectivos fabricantes.

Foram fornecidas dietas à base de milho moído e farelo de soja, suplementadas com minerais e vitaminas. Os níveis de proteína bruta foram fixados em 21,4\% e 19,0\%, e os níveis de energia metabolizável fixados em $3000 \mathrm{kcal} / \mathrm{kg}$ e $3100 \mathrm{kcal} / \mathrm{kg}$, respectivamente, para as fases de 1 a 21 e 22 a 42 dias de idade (Tabela 1), de acordo com as recomendações de Rostagno et al., (2000). Todas as aves foram criadas em cama reutilizada em dois lotes anteriores, objetivando aumentar o desafio aos aditivos promotores de crescimento. Nas dietas não se utilizou nenhum tipo de coccidiostático, sendo os aditivos testados adicionados sobre as rações prontas.

Semanalmente, foram feitas avaliações de desempenho de todas as aves de cada parcela e, ao final do período experimental, todas as aves foram submetidas à avaliação do consumo de ração, ganho de peso, conversão alimentar, eficiência alimentar, fator de produção e viabilidade. Para avaliação de características de carcaça, no final do período experimental, quatro aves por parcela foram identificadas com etiquetas e submetidas a jejum de seis horas. Logo após, as aves foram pesadas e abatidas para análise de rendimento de carcaça. As carcaças foram pesadas sem cabeça, pescoço e pés e o rendimento de carcaça foi obtido com base no peso vivo, o rendimento das partes foi calculado em relação ao peso de carcaça eviscerada (sem pés e cabeça). Para as avaliações microbiológicas, no final do período experimental, foram sacrificadas quatro aves por repetição e coletadas amostras do conteúdo do intestino delgado e cecos das aves, para determinação da contagem total de bactérias. Em cada ave abatida, as seções do intestino e cecos, previamente isoladas e separadas por ligaduras, foram removidas, acondicionadas em sacos plásticos, colocadas em caixa térmica contendo gelo e imediatamente transportadas ao Laboratório de Microbiologia do Setor de Laticínios da Escola Agrotécnica Federal de Inconfidentes. Foi formado um "pool” da digesta de cada segmento, e coletados 5 g do material e imediatamente transferidos para erlenmeyers de $250 \mathrm{ml}$, contendo $45 \mathrm{ml}$ de água peptonada estéril (10 g de peptona; $1000 \mathrm{ml}$ de água destilada). Com base nessa amostra, foi obtida uma diluição de $10^{-1}$, a qual foi utilizada 
para as diluições subseqüentes até $10^{-6}$. Das diluições $10^{-4}$, $10^{-5}$ e $10^{-6}$, foi feito plaqueamento de $0,1 \mathrm{ml}$ de cada diluição e em triplicata em meio PCA (Plate Count Agar) constituído de 5,0 g de triptona; 2,5 g de extrato de levedura; 1,0 g de glicose; $12,0 \mathrm{~g}$ de ágar; $1000 \mathrm{ml}$ de água destilada; $\mathrm{pH} 7,0 \pm 0,2$. As placas foram incubadas 48 horas a $32^{\circ}$ $\mathrm{C}$; posteriormente foi feita a contagem das unidades formadoras de colônia (UFC/g). O delineamento utilizado foi inteiramente casualizado em um esquema fatorial $7 \times 2$, correspondente a 7 fontes de aditivos (antibiótico, basal, MOS, FOS, ácido fumárico, cogumelo desidratado, probiótico) e 2 sexos (macho e fêmea) com 4 repetições de 30 aves por unidade experimental, alojadas em boxes de $4,4 \mathrm{~m}^{2}$ por um período de 1 a 42 dias de idade.

A avaliação estatística do experimento foi realizada segundo o seguinte modelo estatístico:

$$
\mathbf{Y}_{\mathrm{ijk}}=\boldsymbol{\mu}+\mathbf{A}_{\mathbf{i}}+\mathrm{S}_{\mathbf{j}}+\mathbf{A S}_{\mathrm{ij}}+\mathbf{e}_{\mathbf{i j k}}
$$

$\mathbf{Y}_{\mathbf{i j k}}$ : observação $\mathbf{k}$ referente ao aditivo $\mathbf{i}$ no sexo $\mathbf{j}$;

$\boldsymbol{\mu}$ : uma constante associada a todas as observações;

$\mathbf{A}_{\mathbf{i}}$ efeito do aditivo i, com i = 1, 2, 3, 4, 5, 6 e 7;

$S_{j}$ : efeito do sexo $j$, com $j=1$ e 2;

$\mathbf{A S}_{\mathrm{ij}}$ : efeito da interação entre aditivo $\mathbf{i}$ e sexo $\mathbf{j}$;

$\mathbf{e}_{\mathrm{ijk}}$ : erro experimental aleatório associado a cada observação, que por pressuposição, é normal e independente distribuído com média 0 e variância $\sigma^{2}$.

Os resultados foram comparados mediante da análise de variância, utilizando-se o pacote computacional SISVAR (Sistema de Análise de Variância para dados Balanceados), segundo Ferreira (2000). As médias foram comparadas pelo teste de Scott Knott ao nível de $5 \%$ de probabilidade.

\section{RESULTADOS E DISCUSSÃO}

Os resultados de consumo de ração (g), ganho de peso (g), conversão alimentar, eficiência alimentar $(\mathrm{kg} / \mathrm{kg})$, fator de produção e viabilidade (\%) estão expressos nas Tabelas 2 e 3. Observou-se que a utilização de antibióticos e aditivos promotores de crescimento não promoveu melhoria significativa $(\mathrm{P}>0,05)$ no consumo de ração e ganho de peso, o que possivelmente pode ser atribuído às boas condições de manejo e de qualidade das rações. Estes resultados estão de acordo com Dionízio (2001), que não observou efeitos sobre essas variáveis quando do uso de antibióticos e prebióticos. Porém, estes resultados são discordantes dos obtidos por Berrtechini e Hossain (1993) e Henrique et al., (1998), que observaram maior consumo de ração e ganho de peso em aves que receberam antibióticos e probióticos nas dietas.

Os machos apresentaram melhores resultados aos 42 dias de idade em comparação às fêmeas, em todos os tratamentos $(\mathrm{P}<0,05)$. Estes resultados são similares aos de Loddi et al., (2000). As aves que receberam MOS e FOS apresentaram melhor conversão alimentar em relação aos outros tratamentos, possivelmente pela redução de pH e adsorção de cepas bacterianas patogênicas, reduzindo a colonização destas e melhorando os processos de digestão e absorção de nutrientes (APAJAHATI e BEDFORD, 1999). Esses resultados estão de acordo com Leedle (2000), que ao avaliar o efeito de MOS como promotor de crescimento, observou melhor desenvolvimento da microbiota intestinal, o que resultou em melhor desempenho das aves. Porém, esses dados são discordantes dos obtidos por Dionízio (2001), que não observou efeito da manose sobre a conversão alimentar. Independente do aditivo utilizado, os machos apresentaram melhor conversão alimentar.

Quanto à viabilidade, não foram observadas diferenças significativas $(\mathrm{P}>0,05)$ entre os aditivos. No entanto, as fêmeas apresentaram maior viabilidade, devido ao fato dos machos apresentarem um crescimento corpóreo mais rápido e apresentarem maior susceptibilidade a problemas cardio-pulmonares, o que pode ter influenciado na mortalidade. Esses dados são discordantes dos obtidos por Henrique et al., (1998), que observaram uma redução da mortalidade em aves que receberam probióticos nas rações.

Observou-se maior eficiência alimentar nas aves que receberam prebióticos (MOS e FOS), em comparação às que receberam outros aditivos. Possivelmente, os prebióticos causaram uma redução do $\mathrm{pH}$ intestinal, deprimindo o crescimento de microrganismos patogênicos e favorecendo uma microbiota intestinal benéfica, o que representou resultados significativos no desempenho produtivo das aves em condições de desafio sanitário. Estes dados não estão de acordo com os observados por Corrêa et al., (2000) e Dionízio (2001), que não observaram alterações na eficiência alimentar.

Observou-se que o fator de produção foi melhor no grupo de aves que recebeu MOS em relação aos outros tratamentos. Esses resultados podem estar relacionados a uma menor taxa de mortalidade e às boas condições de manejo. Tais resultados, estão de acordo com os de Henrique et al., (1998) e Santos et al., (2002b). 
TABELA 1 - Composição e valores nutricionais da dieta basal.

\begin{tabular}{lcc}
\hline \multicolumn{1}{c}{ INGREDIENTE } & Fase inicial $^{\mathbf{1}}$ & Fase final $^{\mathbf{1}}$ \\
\hline Milho & 55,890 & 62,245 \\
Farelo de soja & 35,950 & 29,400 \\
Óleo de soja & 3,435 & 3,820 \\
Fosfato bicálcico & 1,750 & 1,650 \\
Calcário calcítico & 1,020 & 0,950 \\
Cloreto de colina (60\%) & 0,050 & 0,050 \\
DL-metionina & 0,165 & 0,150 \\
L-lisina & 0,052 & 0,150 \\
Sal comum & 0,450 & 0,382 \\
Suplemento vitamínico ${ }^{2}$ & 0,100 & 0,100 \\
Suplemento mineral ${ }^{2}$ & 0,100 & 0,100 \\
Caulin & 1,038 & 1,002 \\
TOTAL & 100,00 & 100,00 \\
\hline COMPOSIÇÃO NUTRITIVA & & \\
\hline EM(Kcal/kg) & 3.000 & 3.100 \\
Proteína bruta (\%) & 21,48 & 19,03 \\
Metionina + cistina (\%) & 0,890 & 0,820 \\
Lisina (\%) & 1,180 & 1,090 \\
Fósforo Disp. (\%) & 0,470 & 0,440 \\
Cálcio (\%) & 0,980 & 0,900 \\
Sódio (\%) & 0,219 & 0,190 \\
\hline Os aditvos ben & substituça a matera
\end{tabular}

${ }^{1}$ Os aditivos beneficiadores do crescimento foram suplementados nas rações em substituição ao material inerte (caulin).

${ }^{2}$ Polimix (FATEC S/A): Vitamina A (5.500.000UI), Vitamina $D_{3}(1.000 .000$ UI), Vitamina E (6.500 mg), Vitamina $K_{3}(1.250 \mathrm{mg})$, Vitamina $B_{1}(500 \mathrm{mg})$, Vitamina $B_{2}(2.500 \mathrm{mg})$, Vitamina $B_{6}(750 \mathrm{mg})$, Vitamina $B_{12}$ $(7.500 \mu \mathrm{g})$, Ácido fólico $(250 \mathrm{mg})$, Ácido pantotênico $(6.500 \mathrm{mg})$, Biotina $(25 \mathrm{mg})$, Niacina $(17.500 \mathrm{mg})$, Selênio (100 mg), Iodo (500 mg), Ferro (25.000 mg), Cobre (3.000 mg), Zinco (22.500 mg), Cobalto (50 mg), Manganês (32.500 mg) e Antioxidante (2.000 mg).

Os resultados de peso ao abate (PA), rendimento de carcaça (RC) e rendimento de peito (RP) estão expressos na Tabela 4. Observou-se na interação $(\mathrm{P}<0,05)$ entre aditivo e sexo que o maior peso de abate ocorreu quando do uso de antibiótico, MOS e FOS para os machos em relação aos outros aditivos, porém, sem efeito para as fêmeas. O comportamento do peso ao abate em função do aditivo foi diferente em relação ao sexo, observando-se menor peso de abate nas fêmeas quando do uso de antibiótico e prebiótico (MOS e FOS) em relação aos outros aditivos. O maior peso de abate para os machos, possivelmente, está relacionado com o crescimento mais rápido e maior voracidade de consumo de ração, que conferiu maior deposição de proteína corporal e ganho de peso. 
TABELA 2 - Desempenho de frangos de corte, machos e fêmeas, alimentados com diferentes aditivos no período de 1 a 42 dias de idade.

\begin{tabular}{lccc}
\hline \multicolumn{1}{c}{ Aditivo } & Consumo de ração (g) & Ganho de peso (g) & Conversão alimentar \\
\hline Basal (sem aditivo) & 4488 & 2331 & $1,92 \mathrm{~B}$ \\
Antibiótico & 4524 & 2347 & $1,92 \mathrm{~B}$ \\
MOS & 4367 & 2416 & $1,80 \mathrm{C}$ \\
FOS & 4394 & 2323 & $1,88 \mathrm{C}$ \\
Ácido fumárico & 4516 & 2276 & $1,98 \mathrm{~A}$ \\
Cogumelo desidratado & 4454 & 2320 & $1,92 \mathrm{~B}$ \\
Probiótico & 4515 & 2360 & $1,90 \mathrm{~B}$ \\
\hline Macho & $4592 \mathrm{a}$ & $2446 \mathrm{a}$ & $1,87 \mathrm{~b}$ \\
Fêmea & $4339 \mathrm{~b}$ & $2232 \mathrm{~b}$ & $1,94 \mathrm{a}$ \\
\hline Média geral & 4465 & 2339 & 1,90 \\
\hline CV (\%) & 3,64 & 4,66 & 2,87 \\
\hline
\end{tabular}

Médias com letras maiúsculas distintas, na mesma coluna, diferem $(\mathbf{P}<\mathbf{0 , 0 5})$ pelo teste Scott-Knott. Médias com letras minúsculas distintas, na mesma coluna, diferem $(P<0,05)$ pelo teste $F$.

TABELA 3 - Eficiência alimentar, viabilidade e fator de produção, machos e fêmeas, alimentados com diferentes aditivos no período de 1 a 42 dias de idade.

\begin{tabular}{lccc}
\hline \multicolumn{1}{c}{ Aditivo } & Eficiência alimentar (kg/kg) & Fator de produção & Viabilidade (\%) \\
\hline Basal (sem aditivo) & 0,51 B & 284,87 B & 97,00 \\
\hline Antibiótico & 0,51 B & 277,87 B & 98,75 \\
MOS & 0,55 A & 315,37 A & 99,12 \\
FOS & 0,54 A & 292,00 B & 95,25 \\
Ácido fumárico & 0,50 B & 265,37 B & 97,37 \\
Cogumelo desidratado & 0,51 B & 273,50 B & 95,62 \\
Probiótico & 0,51 B & 278,12 B & 97,37 \\
\hline Macho & 0,53 a & 299,07 a & 96,17 b \\
Fêmea & 0,51 b & 268,67 b & 98,25 a \\
\hline Média geral & 0,52 & 283,87 & 97,21 \\
\hline CV (\%) & 3,65 & 9,23 & 3,68 \\
\hline
\end{tabular}

Médias com letras maiúsculas distintas, na mesma coluna, diferem $(P<0,05)$ pelo teste Scott-Knott. Médias com letras minúsculas distintas, na mesma coluna, diferem $(\mathbf{P}<0,05)$ pelo teste $\mathrm{F}$. 
TABELA 4 - Peso ao abate, rendimento de carcaça ${ }^{1}$ e peito de frangos de corte machos e fêmeas, alimentados com diferentes aditivos no período de 1 a 42 dias de idade.

\begin{tabular}{lcccc}
\hline \multirow{2}{*}{ Aditivo } & \multicolumn{2}{c}{ Peso ao abate (g) } & Rendimento de carcaça (\%) & Peito (\%) \\
\cline { 2 - 5 } & Macho & Fêmea & \\
\hline Basal (sem aditivo) & $2502 \mathrm{~B} \mathrm{a}$ & $2399 \mathrm{~A} \mathrm{a}$ & $70,44 \mathrm{~B}$ & $31,07 \mathrm{~B}$ \\
Antibiótico & $2654 \mathrm{~A} \mathrm{a}$ & $2279 \mathrm{~A} \mathrm{~b}$ & $70,09 \mathrm{~B}$ & $32,53 \mathrm{~A}$ \\
MOS & $2833 \mathrm{~A} \mathrm{a}$ & $2194 \mathrm{~A} \mathrm{~b}$ & $69,00 \mathrm{~B}$ & $32,91 \mathrm{~A}$ \\
FOS & $2681 \mathrm{~A} \mathrm{a}$ & $2339 \mathrm{~A} \mathrm{~b}$ & $70,60 \mathrm{~B}$ & $30,82 \mathrm{~B}$ \\
Ácido fumárico & $2356 \mathrm{~B} \mathrm{a}$ & $2204 \mathrm{~A} \mathrm{a}$ & $74,65 \mathrm{~A}$ & $31,53 \mathrm{~B}$ \\
Cogumelo desidratado & $2503 \mathrm{~B} \mathrm{a}$ & $2329 \mathrm{~A} \mathrm{a}$ & $73,10 \mathrm{~A}$ & $31,74 \mathrm{~B}$ \\
Probiótico & $2389 \mathrm{~B} \mathrm{a}$ & $2318 \mathrm{~A} \mathrm{a}$ & $72,59 \mathrm{~A}$ & $30,72 \mathrm{~B}$ \\
\hline Macho & 2560 & - & 70,62 & 31,63 \\
Fêmea & - & 2294 & 72,38 & 31,70 \\
\hline Média geral & \multicolumn{2}{c}{2427} & 71,50 & 31,62 \\
\hline CV (\%) & \multicolumn{3}{c}{6,98} \\
\hline
\end{tabular}

Médias com letras maiúsculas distintas, na mesma coluna, diferem $(P<0,05)$ pelo teste Scott-Knott.

Médias com letras minúsculas distintas, na mesma linha, diferem $(\mathbf{P}<\mathbf{0 , 0 5})$ pelo teste $\mathrm{F}$.

${ }^{1}$ Carcaça eviscerada sem cabeça, pescoço e pés.

Quanto ao rendimento de carcaça, verificou-se melhores resultados nas aves que receberam ácido fumárico, cogumelo desidratado e probiótico na ração em relação aos outros aditivos. Este fato pode ser devido a uma melhor ação permissora desses aditivos no trato gastrointestinal, que proporcionou melhor utilização da proteína e energia no metabolismo intermediário destas aves. Não foi observado efeito do sexo sobre o rendimento de carcaça. Esses resultados estão de acordo com os encontrados por Corrêa et al., (2000), que obtiveram melhores respostas dos machos quando utilizaram antibióticos na ração. No entanto, esses dados são discordantes dos obtidos por Runho (1995), que não observou efeito do ácido fumárico sobre o rendimento de carcaça em frangos de corte. Da mesma forma, Dionízio (2001) não observou efeito da adição de prebióticos e antibiótico à dieta sobre o rendimento de carcaça de frangos de corte.

Apesar de não ter sido observado efeito do sexo $(\mathrm{P}>0,05)$, verificou-se maior rendimento de peito quando se utilizou antibiótico e MOS, em comparação aos demais tratamentos. Estes resultados foram coerentes com os de peso ao abate, o que pode ser atribuído ao nível de lisina utilizado na dieta, que possivelmente propor- cionou uma ação permissora na formação das estruturas musculares, ou talvez pelo fator lipotrópico. Resultados semelhantes foram encontrados por Corrêa et al., (2000), enquanto Loddi et al., (2000) e Dionízio (2001) não observaram diferenças no peso ao abate. Os resultados do rendimento de coxa (RCX), rendimento de sobrecoxa (RSCX), rendimento de asa (RASA) e rendimento de gordura abdominal (RGABD) são apresentados na Tabela 5. Não foram observadas diferenças $(\mathrm{P}>0,05)$ nos rendimentos de asa e coxa entre os aditivos utilizados. No entanto, considerando o fator sexo, os machos apresentaram maior rendimento de coxa, o que não ocorreu com o rendimento de sobrecoxa.

As aves suplementadas com antibiótico, MOS, cogumelo desidratado e probiótico apresentaram maior rendimento de sobrecoxa, em comparação às que receberam dieta basal, ácido fumárico e FOS, sugerindo que tenha havido uma deposição de nutrientes maior que os demais tratamentos. Isso indica que essas aves tiveram capacidade de manter maiores taxas de crescimento e altas taxas de retenção protéica.

Tal fato se deve talvez, a composição corporal que sofre mudanças durante o crescimento, tanto em 
Uso de aditivos promotores de crescimento sobre o desempenho...

TABELA 5 - Rendimento de partes, machos e fêmeas, alimentados com diferentes aditivos no período de 1 a 42 dias de idade.

\begin{tabular}{lcccc}
\hline \multicolumn{1}{c}{ Aditivo } & Coxa (\%) & Sobrecoxa (\%) & Asa (\%) & Gordura abdominal (\%) \\
\hline Basal (sem aditivo) & 14,08 & $14,94 \mathrm{~B}$ & 10,43 & 2,13 \\
\hline Antibiótico & 14,96 & $16,31 \mathrm{~A}$ & 10,34 & 2,07 \\
MOS & 14,32 & $15,70 \mathrm{~A}$ & 10,68 & 2,16 \\
FOS & 13,89 & $14,74 \mathrm{~B}$ & 11,07 & 2,22 \\
Ácido fumárico & 14,10 & $14,36 \mathrm{~B}$ & 11,35 & 1,73 \\
Cogumelo desidratado & 13,84 & $15,37 \mathrm{~A}$ & 11,04 & 2,26 \\
Probiótico & 13,49 & $15,50 \mathrm{~A}$ & 10,82 & 2,46 \\
\hline Macho & $14,49 \mathrm{a}$ & 15,49 & 10,83 & $1,04 \mathrm{~b}$ \\
Fêmea & $13,71 \mathrm{~b}$ & 15,06 & 10,81 & $2,45 \mathrm{a}$ \\
\hline Média geral & 14,10 & 15,28 & 10,82 & 2,15 \\
\hline CV (\%) & 6,21 & 6,40 & 7,61 & 22,14 \\
\hline
\end{tabular}

Médias com letras maiúsculas distintas, na mesma coluna, diferem $(\mathbf{P}<\mathbf{0 , 0 5})$ pelo teste Scott-Knott. Médias com letras minúsculas distintas, na mesma coluna, diferem $(\mathbf{P}<0,05)$ pelo teste $F$.

termos químicos quanto físicos, embora a taxa de ganho de diferentes componentes corpóreos não seja diretamente proporcional à taxa de crescimento a diferentes pesos. Dados contraditórios foram encontrados por Loddi et al., (2000), que não verificaram efeitos do uso de antibiótico e probiótico para o mesmo parâmetro em frangos de corte, porém, Corrêa et al., (2000) observaram efeitos significativos de antibiótico e probiótico sobre esse parâmetro, nos machos.

Com relação à gordura abdominal, o uso de aditivos resultou em uma redução média de $22 \%$ de gordura abdominal em relação ao antibiótico, porém, esta diferença não foi significativa $(P>0,05)$. No entanto, as aves fêmeas apresentaram maior deposição de gordura abdominal $(57,0 \%)$ em relação aos machos. Isso pode ser devido aos machos apresentarem maior eficiência na retenção protéica e potencial em depositar tecido magro, evidenciando um efeito da ação lipolítica quando suplementados com estes aditivos.

Os resultados da contagem bacteriana total do intestino delgado e cecos estão expressos na Tabela 6 . Observou-se que a utilização de antibiótico reduziu $(\mathrm{P}<0,05)$ a população bacteriana, em comparação aos aditivos promotores de crescimento. Esse resultado, associado ao menor número de bactérias, sugere que houve um controle da microbiota intestinal e que possivelmente, a contagem total de bactérias não se alterou. Porém, pode ter havido mudanças na proporção de algumas espécies, o que influenciou em mudanças no metabolismo dos microrganismos.

Todos os aditivos promotores de crescimento proporcionaram maior contagem total de bactérias em relação ao antibiótico, exceto o acido fumárico, que apresentou resultados semelhantes aos do antibiótico para o intestino e cecos. Apesar de dados da literatura descreverem as espécies que compõem a microbiota de diferentes segmentos do trato gastrointestinal, Leedle (2000) afirmou que possivelmente não existe uma microbiota típica, uma vez que a composição do alimento, as condições ambientais, a presença de drogas e patógenos afetam de maneira diferente as espécies de bactérias. Esses resultados são semelhantes aos encontrados por Dionízio (2001), que avaliou a utilização de antibiótico, prebiótico e probióticos como promotores de crescimento. Porém, esses dados estão abaixo dos obtidos por Apajahat e Bedford (1999), que mostraram que a densidade populacional de bactérias no intestino das aves é de aproximadamente $109 \mathrm{UFC/g}$ e, nos cecos, de 1011 UFC/g. Não houve diferença $(P>0,05)$ entre sexos quanto à contagem de bactérias, sugerindo que tanto os machos quanto às fêmeas apresentaram uma manutenção estável das populações de bactérias, seguindo uma sucessão de alguns tipos de microrganismos e declínio de outros. 
SANTOS, E. C. dos et al.

TABELA 6 - Contagem total de bactérias em amostras de intestino delgado e cecos, machos e fêmeas, alimentados com diferentes aditivos no período de 1 a 42 dias de idade.

\begin{tabular}{lcc}
\hline \multicolumn{1}{c}{ Aditivo } & Intestino delgado Log (UFC/g) & Cecos Log (UFC/g) \\
\hline Basal (sem aditivo) & $7,63 \mathrm{C}$ & $8,85 \mathrm{~B}$ \\
\hline Antibiótico & $7,23 \mathrm{D}$ & $7,39 \mathrm{E}$ \\
MOS & $8,41 \mathrm{~A}$ & $8,46 \mathrm{C}$ \\
FOS & $8,52 \mathrm{~A}$ & $8,67 \mathrm{C}$ \\
Ácido fumárico & $7,32 \mathrm{D}$ & $7,37 \mathrm{E}$ \\
Cogumelo desidratado & $8,13 \mathrm{~B}$ & $8,17 \mathrm{D}$ \\
Probiótico & $8,33 \mathrm{~A}$ & $9,27 \mathrm{~A}$ \\
\hline Macho & 7,93 & 8,34 \\
Fêmea & 7,94 & 8,28 \\
\hline Média geral & 7,94 & 8,31 \\
\hline CV (\%) & 2,93 & 2,55 \\
\hline
\end{tabular}

Médias com letras maiúsculas distintas, na mesma coluna, diferem $(P<0,05)$ pelo teste Scott-Knott.

\section{CONCLUSÃO}

Os aditivos promotores de crescimento podem ser usados na alimentação para frangos de corte, em substituição ao antibiótico, sem comprometer o desempenho e características de carcaça, no período de 1 a 42 dias de idade.

\section{REFERÊNCIAS BIBLIOGRÁFICAS}

APAJAHATI, J.; BEDFORD, M. R. Improve bird performance by feeding its microflora. World Poultry Surrey, [S.l.], v. 15, n. 2, p. 20-23, 1999.

BERRTECHINI, A. G.; HOSSAIN, S. M. Utilização de um tipo de probiótico como promotor de crescimento em rações de frangos de corte. In: CONFERÊNCIA APINCO DE CIÊNCIA E TECNOLOGIA AVICOLA, 1993, Santos, SP. Anais... Santos: APINCO, 1993. p. 1.

CORRÊA, G. et al. Desempenho de frangos de corte alimentados com diferentes promotores de crescimento. In: REUNIÃO ANUAL DA SOCIEDADE BRASILEIRA DE ZOOTECNIA, 37., 2000, Viçosa, MG. Anais... Viçosa: SBZ, 2000. CD-ROM.
DIONIZIO, M. A. Prebióticos como promotores de crescimento para frangos de corte. 2001. 60 p. Dissertação (Mestrado em Zootecnia) - Universidade Federal de Lavras, Lavras, 2001.

FERREIRA, D. F. Sistema de análise de variância de dados balanceados SISVAR: pacote computacional. Lavras: UFLA/DEX, 2000.

FUINI, M. G. Utilização do cogumelo Agaricus blazei como alternativa ao uso de antibióticos em rações para frangos de corte. 2001. 64 p. Dissertação (Mestrado em Zootecnia) - Universidade Federal de Lavras, Lavras, 2001.

HENRIQUE, A. P. F. et al. Uso de probióticos e antibióticos como promotores de crescimento para frangos de corte. In: REUNIÃO ANUAL DA SOCIEDADE BRASILEIRA DE ZOOTECNIA, 35., 1998, Botucatu, SP. Anais... Botucatu: SBZ, 1998. p. 297-299.

LEEDLE, J. Intestinal microbiology: action mechanisms. In: SIMPÓSIO SOBRE ADIT1VOS ALTERNATIVOS NA NUTRIÇÃO ANIMAL, 2000, Campinas. Anais... Campinas: CNBA 2000. p. 1-14. 
LODDI, M. M. et al. Uso de probiótico e antibiótico sobre o desempenho, rendimento e a qualidade de carcaça de frangos de corte. Revista Brasileira de Zootecnia, Viçosa, v. 29, n. 4, p. 1124-1131, 2000.

ROSTAGNO, L. I. S. et al. Composição de alimentos e exigências nutricionais: tabelas brasileiras. Viçosa: UFV, 2000. 141 p.

RUNHO, R. C. Uso do ácido orgânico (ácido fumárico) nas rações de frangos de corte. Jaboticabal: Faculdade de Ciências Agrárias e Veterinárias, 1995. 54 f. Apostila.
SANTOS, E. C. et al. Uso de aditivos beneficiadores de crescimento sobre o desempenho de frangos de corte. In: REUNIÃO ANUAL DA SOCIEDADE BRASILEIRA DE ZOOTECNIA, 39., 2002, Recife. Anais... Recife: SBZ, 2002a. CD-ROM.

SANTOS, E. C. et al. Efeitos dos aditivos beneficiadores de crescimento sobre bactérias totais, $\mathrm{pH}$ intestinal e $\mathrm{pH}$ das rações de frangos de corte. In: REUNIÃO ANUAL DA SOCIEDADE BRASILEIRA DE ZOOTECNIA, 39., 2002, Recife. Anais... Recife: SBZ, 2002b. CD-ROM. 